\title{
Article
}

\section{Two Kinds of Flow Modification in HDPE Polymerized by Standard Phillips Cr/Silica Catalyst}

\author{
Takaaki HATTORI $^{*}$, Masataka SUGIMOTO**, and Kiyohito KOYAMA* \\ "Research \& Development Center, Japan Polyethylene Co., 2-3-2, Yako, Kawasaki-ku, Kawasaki 210-8548, Japan \\ ** Yamagata University, 4-3-16, Jonan, Yonezawa, Yamagata 992-8510, Japan
}

(Received : April 26, 2013)

\begin{abstract}
Modifications of rheological and mechanical properties by various kneading methods and histories were studied for high density polyethylene (HDPE) polymerized by a standard Phillips Cr/silica catalyst. The HDPE exhibits long-time relaxation in linear viscoelasticity and apparent strain-hardening in elongational viscosity due to long chain branches. These rheological features were depressed by single-screw extrusion. This phenomenon is known as "shear modification". However, we found that the depressed property could be recovered quickly and easily by tworoll milling. This probably means that different modification being contrary to shear modification exists. The sample processed by an internal batch mixer with a low fill factor showed similar properties to the one kneaded by the tworoll mill, however, another sample processed with a high fill factor was close to the one prepared by the single-screw extruder. It is likely that the ratio influences the balance of convergent flow and shear flow which are generated between two counter-rotating blades and between each blade and the casing, respectively. Since convergent flow contains elongational flow, the modification which should be distinguished from shear modification may be called "elongational modification". Furthermore, stress crack resistance changed as well as rheological properties in spite of no change of Charpy and tensile impact strength.
\end{abstract}

Key Words: Long chain branch / Elongational viscosity / Shear modification / Stress crack resistance

\section{INTRODUCTION}

Rheological change by shear history is known as "shear modification" for long chain branch polymers. ${ }^{1-6)}$ In most reports, low density polyethylene (LDPE) samples were studied. It was said that melt flow index increased, swell ratio or elongational viscosity decreased with shear history in spite of no change of the original molecular characteristics. Rheological properties were gradually recovered by heat treatment when the samples were annealed in molten quiescent state, or they were fully reverted by solution treatment when the samples were re-precipitated from solution in hot xylene.

Hanson ${ }^{1)}$ mentioned that shear modification depressed environmental stress crack resistance of LDPE, while it was recovered by solution-treatment. Munstedt ${ }^{3)}$ reported similar changes in steady state elongational viscosity of LDPE samples, though uniaxial elongation seemed to be more effective in creating the viscosity decrease than simple shear. Yamaguchi et al. discussed the role of elongational flow to the modification by comparing rheological properties of

*E-mail: Hattori.Takaaki@mm.japanpe.co.jp
LDPE samples and various kinds of conventional processing machines such as a two-roll mill, an internal mixer and a twinscrew extruder with two types of screw configurations. ${ }^{\text {) }}$

In this study, we studied the rheological properties of high density polyethylene (HDPE) samples which were polymerized by a standard Phillips $\mathrm{Cr} /$ silica catalyst and prepared by several kneading or extruding machines and their combinations. We found that the rheological behaviour of the shear modified HDPE was dramatically recovered by the tworoll milling. We considered the key points which affected the rheological changes.

\section{EXPERIMENTAL}

\subsection{Sample Preparation}

High density polyethylene (HDPE) powder which was polymerized by a standard Phillips $\mathrm{Cr} /$ silica catalyst and a slurry method was used in this study. The weight-average molecular weight $M w$ and the number-average molecular weight $M n$ were $2.6 \times 10^{5}$ and $2.2 \times 10^{4}$, respectively. Around $0.4 \mathrm{~mol} \%$ of 1 -hexene was co-polymerized. It is said that the HDPE polymerized by Phillips catalyst exhibits long time relaxation and apparent strain-hardening in elongational 
viscosity due to a small amount of long chain branches. ${ }^{7-9)}$

The samples in this study were shown in Figure 1. Some of them were repetitively kneaded by the same methods or the other one. The sample codes also show their processing histories.

Three kneading methods were applied. The first was an internal batch mixer with twin non-intermeshing and counterrotating roller rotors (Labo Plastomill 30C150, roller mixer chamber R60, roller blade R60B; Toyo Seiki Seisaku-sho, Ltd.). The operating conditions of the internal batch mixer and their specific energy $E_{s p}$ are shown in Table II. $E_{s p}[\mathrm{kWh} / \mathrm{kg}]$ is defined as the kneading power $[\mathrm{kWh}]$ per unit throughput $[\mathrm{kg} / \mathrm{h}]$. As for the others of IBM-8, the amount of sample per one batch was $40 \mathrm{~g}$ and its fill factor was 0.8 . Here, the fill factor is the ratio of the sample volume to the mixer capacity.

The second was a $20 \mathrm{~mm} \varphi$ single screw extruder with a

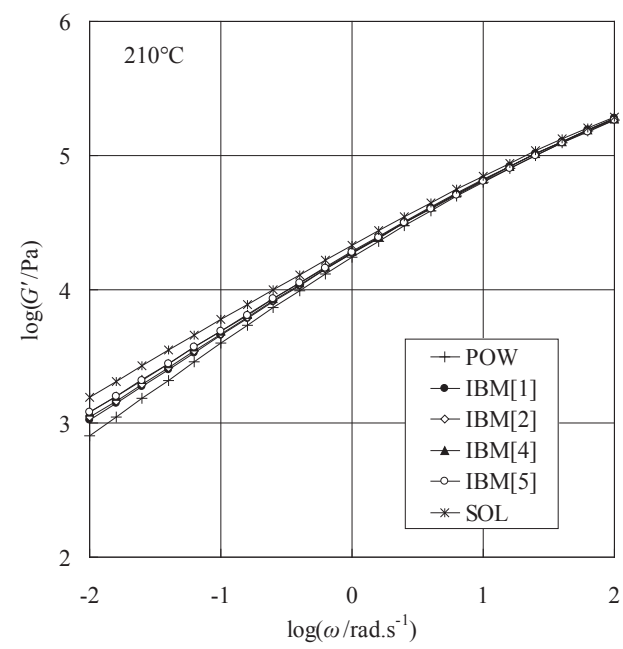

Fig. 1. Influence of specific energy on $G^{\prime}$ curves for an internal batch mixer.

Table I. Kneading methods and histories of samples.

\begin{tabular}{|c|c|c|c|c|c|}
\hline \multirow{2}{*}{ Sample } & \multicolumn{5}{|c|}{ Prcessing History } \\
\hline & $\begin{array}{l}\text { 1st Kneading } \\
\text { Method }\end{array}$ & & $\begin{array}{c}\text { 2nd Kneading } \\
\text { Method }\end{array}$ & & $\begin{array}{c}\text { 3rd Kneading } \\
\text { Method }\end{array}$ \\
\hline $\begin{aligned} & \operatorname{IBM}(1) \\
\sim & \operatorname{IBM}(8)\end{aligned}$ & $\begin{array}{l}\text { Internal Batch } \\
\text { Mixier }\end{array}$ & & - & & - \\
\hline SSE & $\begin{array}{l}\text { Single Screw } \\
\text { Extruder }\end{array}$ & & - & & - \\
\hline $\mathrm{SSE}>\mathrm{SSE}$ & $\begin{array}{l}\text { Single Screw } \\
\text { Extruder }\end{array}$ & $\rightarrow$ & $\begin{array}{l}\text { Single Screw } \\
\text { Extruder }\end{array}$ & & - \\
\hline $\mathrm{SSE}>\mathrm{SSE}>\mathrm{TRM}$ & $\begin{array}{l}\text { Single Screw } \\
\text { Extruder }\end{array}$ & $\rightarrow$ & $\begin{array}{l}\text { Single Screw } \\
\text { Extruder }\end{array}$ & $\rightarrow$ & Two-Roll Mill \\
\hline TRM & Two-Roll Mill & & - & & - \\
\hline $\mathrm{TRM}>\mathrm{SSE}$ & Two-Roll Mill & $\rightarrow$ & $\begin{array}{l}\text { Single Screw } \\
\text { Extruder }\end{array}$ & & - \\
\hline TRM $>$ SSE $>$ TRM & Two-Roll Mill & $\rightarrow$ & $\begin{array}{c}\text { Single Screw } \\
\text { Extruder }\end{array}$ & $\rightarrow$ & Two-Roll Mill \\
\hline PWD & \multicolumn{5}{|c|}{$\begin{array}{l}\text { Powder as polymerized } \\
\text { (only minimum processing for each measurement) }\end{array}$} \\
\hline SOL & \multicolumn{5}{|c|}{$\begin{array}{l}\text { Powder dissolved in hot xylene and recovered from solution } \\
\text { (only minimum processing for each measurement) }\end{array}$} \\
\hline
\end{tabular}

full-flighted screw (Labo Plastomill 30C150, extruder D2020; Toyo Seiki Seisaku-sho, Ltd.). It was operated at $180{ }^{\circ} \mathrm{C}$ and at $40 \mathrm{rpm}$ only. "SSE" and "SSE>SSE" means the samples which were extruded through the single screw extruder once and twice, respectively.

The third was a two-roll mill (Nishimura Machinery Co., Ltd., type NS-200). The diameter of the rolls was $200 \mathrm{~mm}$ and they were rotated at different speeds (20.6 rpm and $24.7 \mathrm{rpm})$. The gap between the rolls was $1 \mathrm{~mm}$. The temperature of roll surface was set at $150{ }^{\circ} \mathrm{C}$. One batch of kneading was $100 \mathrm{~g}$. In the two-roll milling process, a lump of the HDPE in molten state was transformed into a sheet by squeezing between rotating two rolls. The sheet was folded up twice, and thrown into the gap of rolls again. It was repeated for $5 \mathrm{~min}$. It is said that materials are mixed and kneaded by large pressure between two rolls and shear stress generated by the difference of rotational speeds of two rolls. This process is often used for rubber kneading.

For the above-mentioned kneading methods, $0.2 \mathrm{wt} \%$ of a thermal stabilizer (BASF; IRGANOX B225) was added to the samples to prevent oxidative degradation.

For the sample of "SOL", $1 \mathrm{wt} \%$ HDPE powder was dissolved into p-xylene at $120{ }^{\circ} \mathrm{C}$, and quenched with mixture of dry ice and ethanol. After filtration, it was blended with $0.2 \mathrm{wt} \%$ of 2,6-di-t-butyl-4-hydroxytoluene (BHT) as a thermal stabilizer and dried with a vacuum oven. We call above procedures "solution-treatment". "PWD" means aspolymerized HDPE powder with $0.2 \mathrm{wt} \%$ of BHT. Only simple and minimal processes were applied to PWD and SOL for each rheological measurement and mechanical test.

\subsection{Rheological Measurements and Thermal Analysis}

High Load Melt Flow Rate (HLMFR) according to JIS K7210 of each sample was measured at $190{ }^{\circ} \mathrm{C}$ by using a typical melt flow indexer (Melt Indexer L207; Takara Kogyo Co. Ltd.) with $21.6 \mathrm{~kg}$ weight. Swell Ratio $(S R)$ was also checked. $S R$ is defined as follows:

$$
S R=\frac{D-D_{0}}{D_{0}} \times 100
$$

where $D_{0}$ is the die diameter and $D$ is the extrudate diameter.

Oscillatory shear measurements within the linear viscoelastic were carried out at $210{ }^{\circ} \mathrm{C}$ using parallel plates of $25 \mathrm{~mm}$ diameter (ARES; TA Instruments Japan Inc.). The strain was $10 \%$ and the range of angular frequency was from 0.01 to $100 \mathrm{rad} / \mathrm{s}$.

Transient elongational viscosity curves $\eta_{E}^{+}(t)$ were 
obtained at strain rate $0.08 \mathrm{~s}^{-1}$ and $170{ }^{\circ} \mathrm{C}$ by a Meissnertype elongational rheometer (Melten Rheometer; Toyo Seiki Seisaku-sho, Ltd.). Rod-like samples for the measurement were prepared using a capillary rheometer. $L / D$ of the die was $15 / 3[\mathrm{~mm} / \mathrm{mm}]$ and the shear rate was $15 \mathrm{~s}^{-1}$. The specimens were annealed in a silicon oil bath at $170{ }^{\circ} \mathrm{C}$ for 15 minutes prior to the measurements.

Melting temperatures $T_{m}$ were obtained using DSC (DSC-7; PerkinElmer Inc.). Samples were heated to $200{ }^{\circ} \mathrm{C}$, held at $200{ }^{\circ} \mathrm{C}$ for $5 \mathrm{~min}$, cooled at a rate of $20^{\circ} \mathrm{C} / \mathrm{min}$ to $30{ }^{\circ} \mathrm{C}$ and held at $30{ }^{\circ} \mathrm{C}$ for $5 \mathrm{~min}$, and then heated to $200{ }^{\circ} \mathrm{C}$ at a rate of $20{ }^{\circ} \mathrm{C} / \mathrm{min}$. Melting temperatures were obtained from the second heating thermograms.

\subsection{Mechanical Tests}

All of test specimen were prepared according to JIS K7151 by an automatically press machine (Fine Labo Press; Toyo Seiki Seisaku-sho, Ltd.).

Densities were measured by collecting gas over water (Automatic Densimeter; Toyo Seiki Seisaku-sho, Ltd.).

Values of Charpy impact strength according to JIS K7111 were obtained at $23{ }^{\circ} \mathrm{C}$ and $-40{ }^{\circ} \mathrm{C}$. The notch radius was $0.25 \mathrm{~mm}$. Values of tensile impact strength according to JIS $\mathrm{K} 7160$ were obtained at $23{ }^{\circ} \mathrm{C}$ and $-40^{\circ} \mathrm{C}$. The specimen had double V-notch (type 1 ) and the notch radius was $1 \mathrm{~mm}$. These values were measured by using a typical pendulum-type impact tester (Digital Impact Tester; Toyo Seiki Seisaku-sho, Ltd.)

Full Notch Creep Test (FNCT) according to JIS K6774 is a test method to evaluate stress crack resistance of polyethylene. The sample geometry was a square pillar of $6 \times 6 \times 80 \mathrm{~mm}$. $1 \mathrm{~mm}$-depth notches on 4 sides were put into the central part of the sample bar (cf. Figure 10). Remaining section surrounded by the notches was approximately $4 \times 4 \mathrm{~mm}$. Several levels of static loads were imposed. The environmental condition was $80{ }^{\circ} \mathrm{C}$ in the water. Craze cracks were formed at the tips of each notch, then the cracks grew up, and finally the sample was broken into two parts. The system recorded the time to failure. Stress was calculated by dividing the load by the cross section which was measured by using an optical microscope after testing.

\section{RESULTS AND DISCUSSION}

\subsection{Rheological Properties}

Several curves of storage modulus $G^{\prime}$ versus angular frequency $\omega$ and curves of transient elongational viscosity were drawn in Figure 1 and 2, respectively. $G^{\prime}$ at $0.01 \mathrm{rad} / \mathrm{s}$ $\left(G^{\prime}{ }_{0.01}\right)$ and $100 \mathrm{rad} / \mathrm{s}\left(G^{\prime}{ }_{100}\right)$ and the maximum value of elongational viscosity $\eta_{\max }$ of all samples except for IBM-8 in Table II were plotted in Figure 3.

Although $G_{100}^{\prime}$ were almost independent of $E_{s p}, G_{0.01}^{\prime}$ increased with $E_{s p}$ in the kneading process, the solutiontreatment sample (SOL) showed the highest value. $\eta_{\max }$ decreased with increase of $E_{s p}$, however we should note that $\eta_{\max }$ was enhanced by the solution-treatment.

Three $\eta_{E}^{+}(t)$ curves were drawn in Figure 4. In the case of IBM- 8 whose fill factor was 0.4 , its $E_{s p}$ was located between IBM-2 and IBM-4 whose fill factors were 0.8 , however, its $\eta_{\max }$ was clearly larger than the other two. Therefore, for this HDPE which has a few of long-chain branches, the fill factor of the internal mixer is surely more dominant on rheological properties than specific energy.

In Figure $5, \eta_{E}^{+}(t)$ curves which had various flow histories

Table II. Mixing conditions of the internal batch mixer.

\begin{tabular}{ccccccc}
\hline Sample & $\begin{array}{c}\text { Sample } \\
\text { Amount }\end{array}$ & $\begin{array}{c}\text { Fill } \\
\text { Factor }\end{array}$ & $\begin{array}{c}\text { Rotational } \\
\text { Frequency }\end{array}$ & $\begin{array}{c}\text { Mixing } \\
\text { Time }\end{array}$ & $\begin{array}{c}\text { Spesific } \\
\text { Energy }\end{array}$ & $\begin{array}{c}\text { Maximum } \\
\text { Tempreture }\end{array}$ \\
& {$[\mathrm{g}]$} & {$[-]$} & {$[\mathrm{rpm}]$} & {$[\mathrm{min}]$} & {$[\mathrm{kWh} / \mathrm{kg}]$} & {$\left[{ }^{\circ} \mathrm{C}\right]$} \\
\hline IBM[1] & 40 & 0.8 & 20 & 1 & 0.027 & 179 \\
IBM[2] & 40 & 0.8 & 20 & 4 & 0.105 & 182 \\
IBM[3] & 40 & 0.8 & 40 & 2 & 0.104 & 184 \\
IBM[4] & 40 & 0.8 & 40 & 7 & 0.395 & 192 \\
IBM[5] & 40 & 0.8 & 40 & 24 & 1.411 & 193 \\
IBM[6] & 40 & 0.8 & 40 & 60 & 2.726 & 192 \\
IBM[7] & 40 & 0.8 & 80 & 4 & 0.516 & 215 \\
IBM[8] & 20 & 0.4 & 40 & 7 & 0.272 & 182 \\
\hline
\end{tabular}

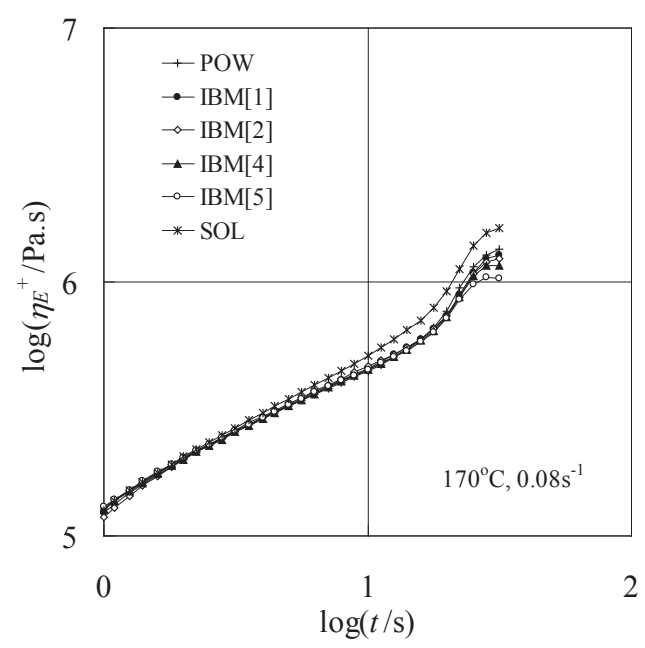

Fig. 2. Influence of specific energy on transient elongational viscosity curves for the internal batch mixer. 
are shown. The strain-hardening of SSE $>$ SSE (the sample processed by the single screw extruder twice) became weaker than that of SSE. The difference was not so large, but it was reproducible and certain. This phenomenon is wellknown as "shear modification". Here, we should note that the strain-hardening feature was much enhanced by two-roll milling than that of SSE. This probably means that different modification which is completely different from "shear modification" exists.

By comparing Figure 4 and 5, it is noted that the curve of the sample processed by the internal mixer with the lower fill factor is similar to the one kneaded by the two-roll mill,

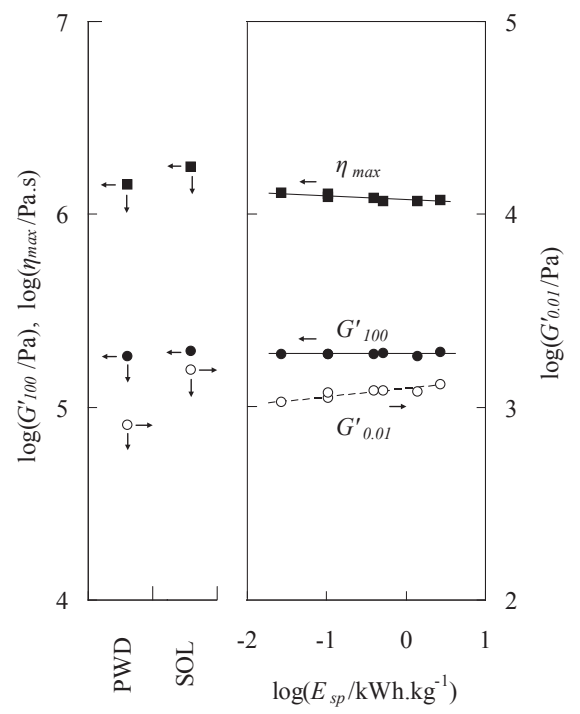

Fig. 3. Dependency of specific energy on $G^{\prime}$ and $\eta_{\max }$ for the internal batch mixer.

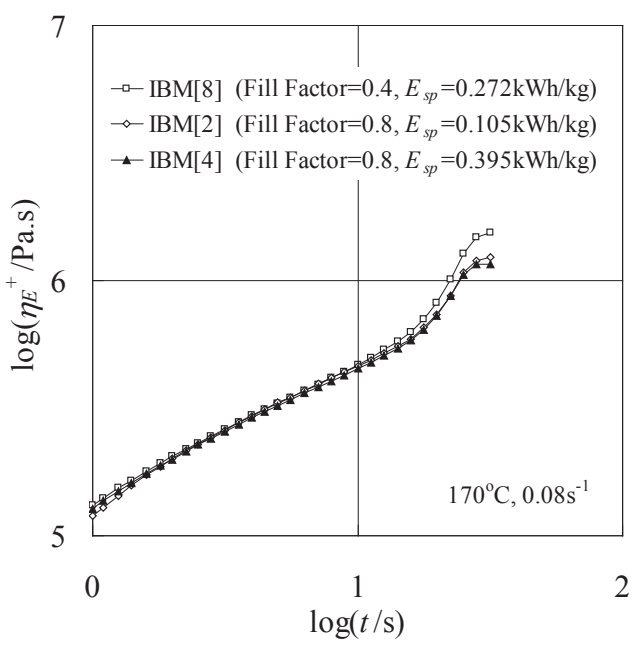

Fig. 4. Influence of fill factor on transient elongational viscosity curves for the internal batch mixer. however, the sample processed with a higher fill factor is close to the one prepared by the single-screw extruder.

It is likely that the fill factor influences the balance of convergent flow and shear flow. The convergent flow is generated between two counter-rotating blades and the shear flow is generated between the blades and the casing. The two-roll milling also includes convergent flow. Because convergent flow can cause elongational flow, the modification which should be distinguished from "shear modification" may be called as "elongational modification".

Figure 6 shows the change of HLMFR and SR during the two-roll milling. "Number of Roll Passage" means the number of times that the sample passed the gap between the rolls. The initial sample whose number of passage was equal to zero was given by the single screw extrusion (SSE). The broken and dotted lines show HLMFR and SR of SSE, respectively. As a

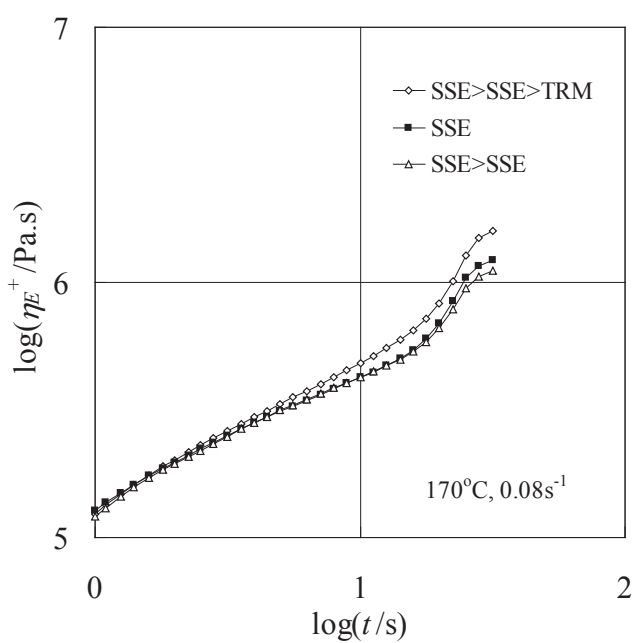

Fig. 5. Influence of flow histories on transient elongational viscosity curves.

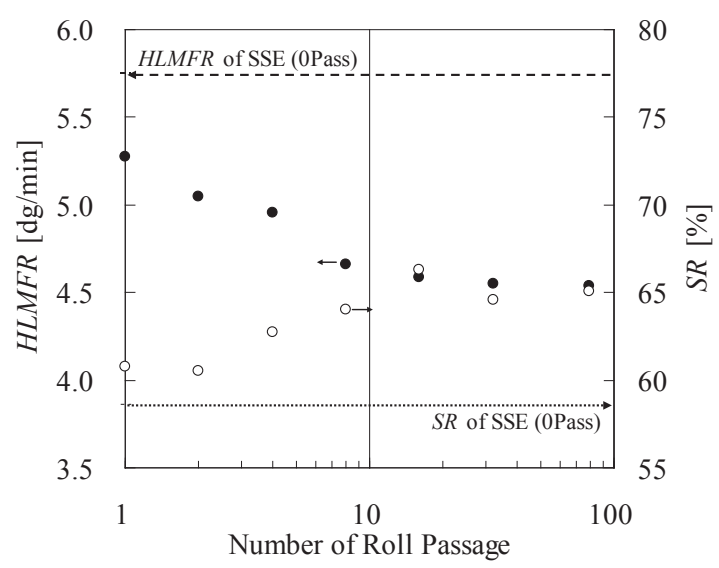

Fig. 6. Dependency of pass number on $H L M F R$ and $S R$ for the two-roll mill mixer. 
kneaded polymer sample might have less uniformity when the number of passage was small, samples for measuring HLMFR and $S R$ were taken from several parts and the values were averaged. The two indexes changed significantly even in first passage. It was reported that recovery from shear modification needed long time when it was annealed in molten quiescent state. $^{1,2,4-6)}$ However, a treatment such as two-roll milling recovered the shear modified properties instantly.

In order to conform the effect of shear flow on rheological behaviour, the sample given by the two-roll milling of aspolymerized the HDPE powder (TRM) was extruded through various capillary dies which had same diameter $(D=1 \mathrm{~mm})$ but had different length $(L=5,10,20,40 \mathrm{~mm})$. The dies were attached to a typical capillary rheometer (INTESCO Co. Ltd.) at $190{ }^{\circ} \mathrm{C}$ and the apparent shear rate was set at $15 \mathrm{~s}^{-1}$. The diameter of its reservoir was $9.55 \mathrm{~mm}$.

Figure 7 shows $H L M F R$ and $S R$ after the capillary extrusions. The broken and dotted lines show HLMFR and SR of TRM, respectively. $H L M F R$ increased with $L$, while $S R$ decreased with $L$. This behaviour seems to be the shear modification as well as seen in single screw extrusion. Thus we can say that shear modification also occurs easily by shear flow even in a capillary.

\subsection{Mechanical Properties}

Values of density, Charpy impact strength, tensile impact strength and melting temperature of the samples which were kneaded by the single screw extruder and the two-roll mill mixer are shown in Table III. There was no apparent difference in mechanical strength between the two. There was, however, clear difference in the failure time in Full Notch Creep Test (FNCT) as shown in Figure 8.

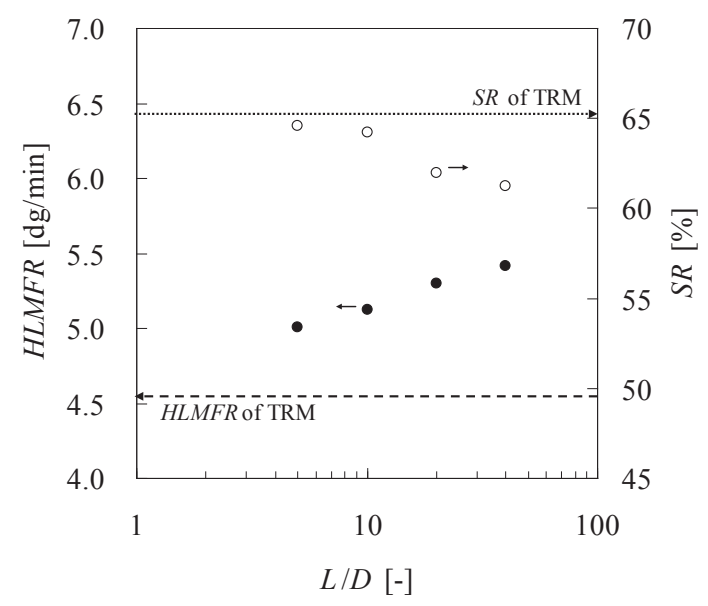

Fig. 7. Dependency of $\mathrm{L} / \mathrm{D}$ on $H L M F R$ and $S R$ for capillary die extrusion.
The sample extruded by the single screw extruder (SSE) had much failure time than the as-polymerized powder sample (POW). Stress crack resistance increased furthermore by tworoll milling. It was thought that molecular orientation in plane occurred for the calendered sheet by two-roll milling, so two types of test pieces were prepared. As shown in Figure 9, the calendered sheets were stacked and compression-molded at $190{ }^{\circ} \mathrm{C}$ so as to be thickness of $6 \mathrm{~mm}$. It is thought that the kneading history still remained after the molding. Subscripts

Table III. Values of density, impact strength and melting temperature for different kneading methods.

\begin{tabular}{|c|c|c|c|c|c|c|}
\hline \multirow{4}{*}{ Sample } & \multirow{4}{*}{$\begin{array}{l}\text { Density } \\
{\left[\mathrm{g} / \mathrm{cm}^{3}\right]}\end{array}$} & \multicolumn{4}{|c|}{ Impact Strength } & \multirow{3}{*}{$\begin{array}{c}\text { Melting } \\
\text { Point }\end{array}$} \\
\hline & & Charpy & Charpy & Tensile & Tensile & \\
\hline & & $23^{\circ} \mathrm{C}$ & $-40^{\circ} \mathrm{C}$ & $23^{\circ} \mathrm{C}$ & $-40^{\circ} \mathrm{C}$ & \\
\hline & & {$\left[\mathrm{kJ} / \mathrm{m}^{2}\right]$} & {$\left[\mathrm{kJ} / \mathrm{m}^{2}\right]$} & {$\left[\mathrm{kJ} / \mathrm{m}^{2}\right]$} & {$\left[\mathrm{kJ} / \mathrm{m}^{2}\right]$} & {$\left[{ }^{\circ} \mathrm{C}\right]$} \\
\hline SSE & 0.945 & $27.0(0.6)$ & $9.6(0.4)$ & $248(26)$ & $164(6)$ & 130.7 \\
\hline TRM & 0.945 & $27.4(1.1)$ & $9.7(0.2)$ & 233 (13) & $155(8)$ & 130.7 \\
\hline
\end{tabular}

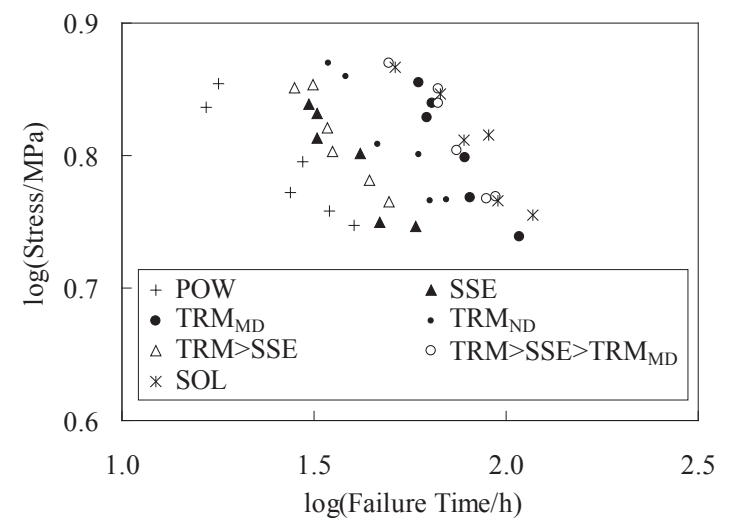

Fig. 8. Relationship between failure time and nominal stress on full notch creep test for various kneaded samples.

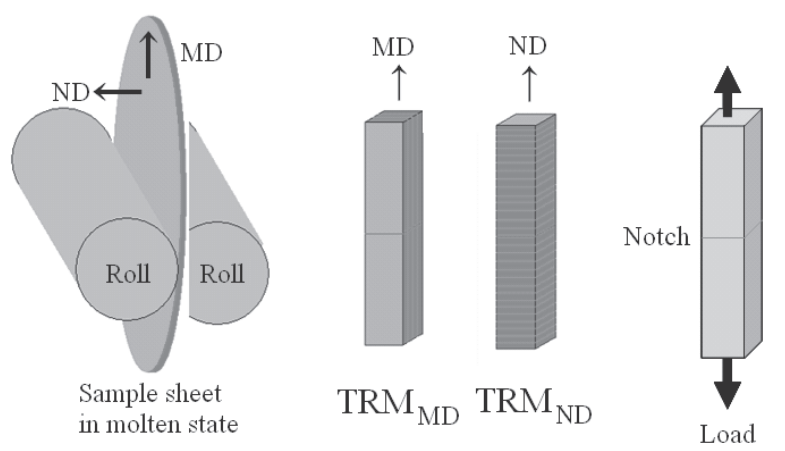

Fig. 9. Schematic diagrams for two directions of roll extrusion sheet and the loading direction of full notch creep test. 
of "ND" and "MD" in the legend mean that the loading direction of FNCT. For example, in the case of $\mathrm{TRM}_{\mathrm{ND}}$, the loading direction is equal to the normal direction of the calendered sheet. The reason why $\mathrm{TRM}_{\mathrm{ND}}$ showed shorter failure time than $\mathrm{TRM}_{\mathrm{MD}}$ would be that the cracks propagated in parallel to oriented molecular chains in the former. Failure time of SSE was shorter than TRM even in the normal direction. The solution-treatment sample (SOL) displayed maximum stress crack resistance.

It is well-known that polymer chain characteristics such as molecular weight, co-monomer content and the distributions of molecular weight and composition affect the failure time because those parameters influence tie-molecule fraction. The tie-molecule theory is a popular concept when stress crack resistance of polyethylene is discussed. The probability of tiechain formation $P$ can be determined by following equation proposed by Huang and Brown. ${ }^{10)}$

$$
\begin{aligned}
& P=\frac{1}{3} \frac{\int_{L}^{\infty} r^{2} \exp \left(-b^{2} r^{2}\right) d r}{\int_{0}^{\infty} r^{2} \exp \left(-b^{2} r^{2}\right) d r}, \\
& b^{2}=\frac{3}{2 \bar{r}^{2}}, \quad \bar{r}^{2}=D n l^{2}
\end{aligned}
$$

where $r$ is the end-to-end distance of the random coil in the melt, $\bar{r}$ is the root mean square of the end-end distance. $D$, $\mathrm{n}$ and $l$ are chain extension factor ( $=6.8$ for polyethylene), number of links and the link length $(=0.153 \mathrm{~nm}$ for polyethylene). $L$ is the critical distance required to form a tiemolecule. Since a tie-molecule connects at least two different crystals, $L$ is expressed by $2 L_{c}+L_{a}$, where $L_{c}$ and $L_{a}$ are the lamellar crystal thickness and the amorphous layer thickness, respectively. Long period $L_{p}$ which is detected by Small-angle X-ray scattering (SAXS) is usually divided to $L_{c}$ and $L_{a}$ by using the volume fraction of crystals $\chi_{\mathrm{v}}$ which is calculated from the density as shown in eq.(3).

$$
\chi_{v}=\frac{\rho-\rho_{a}}{\rho_{c}-\rho_{a}}
$$

where $\rho, \rho_{c}$ and $\rho_{a}$ are densities of the sample, crystal and amorphous, respectively.

Molecular weight is used for determining the values of $r . L_{p}$ was not evaluated by SAXS in this study, however, $L_{c}$ can be estimated from Gibbs-Thomson equation, which corresponds to eq.(4), in which the melting temperature is correlated with the thickness of the lamellar crystal.

$$
L_{c}=\frac{2 \sigma_{e} T^{0}{ }_{m}}{\Delta h_{f}\left(T^{0}{ }_{m}-T_{m}\right)}
$$

$L_{c}$ would be the same in all samples because $T_{m}$ did not depend on kneading method as shown in Table III. Density also did not depend on kneading methods, so that $L_{a}$ of all samples would be the same. $2 L_{c}+L_{a}$ should be also the same consequently.

For example, when the values of $T^{0}{ }_{m}=142^{\circ} \mathrm{C}(415 \mathrm{~K})$ and $\sigma / \Delta h_{f}=2.04 \times 10^{-1} \mathrm{~nm}$ which were used in Weeks' report ${ }^{11)}$ and $T_{m}=130.7^{\circ} \mathrm{C}(403.7 \mathrm{~K})$ in Table III are substituted in eq.(4), $L_{c}$ is calculated to be $15.0 \mathrm{~nm}$. $L_{a}$ is derived to be $9.0 \mathrm{~nm}$ from eq.(3) where it is assumed that $\rho_{c}$ and $\rho_{a}$ are 1.00 and $0.852 \mathrm{~g} / \mathrm{cm}^{3}$, respectively. Therefore the value of $2 L_{c}+L_{a}$ is equal to $39.0 \mathrm{~nm}$. The probability curve of tie-chain formation versus molecular weight for this structural model and molecular weight distribution curve of this HDPE were drawn in Figure 10. It is noticed that the probability increases at less than $10^{5} \mathrm{~g} / \mathrm{mol}$ and it does not reach the maximum value even at $10^{6} \mathrm{~g} / \mathrm{mol}$.

The end-to-end distance $r$ which is generally associated with molecular weight might change by kneading when the relaxation time is long due to long chain branches. Main chain between branching points is stretched in elongational flow. If it relaxed very slowly, $r$ would be larger than the equilibrium state and the probability for forming tie- molecules should increase. Conversely, shear modification decreases the relaxation time, so that chain stretching would become weaker. Furthermore, shear modification is explained by withdrawing a long chain branch to the main chain tube according to the tube model. ${ }^{4)}$ When the withdrawal occurs, two chains exist in a same tube. This means that the molecule does not spread out sufficiently. These conformational varieties might change $r$. The solution-treatment would reset the withdrawal and expand the coil size.

$\mathrm{Lu}$ et al. concluded that a molecular weight greater than $1.5 \times 10^{5}$ is required to create the number of tie-molecules that is necessary to produce high resistance to slow crack growth

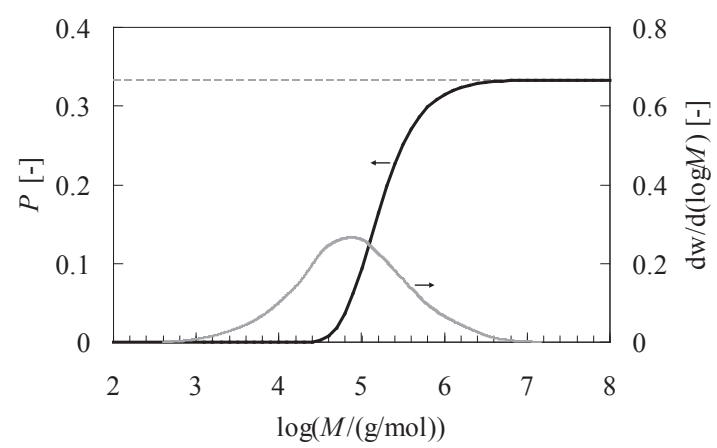

Fig. 10. Dependency of molecular weight on the probability curve of tiechain formation. 
in their particular polyethylene. ${ }^{12)}$ Yoshikawa et al. presented that a column-fractionated Phillips HDPE sample whose molecular weight was more than $10^{5}$ had larger $\eta_{0}$ than those of the other samples which located on a straight line whose slope was 3.5 on the $\log M_{w}-\log \eta_{0}$ graph. ${ }^{13)}$ This says that long chain branches exist in higher molecular weight fraction in the Phillips HDPE. These suggest that above-mentioned flow modifications are caused by the conformational change of higher molecular weight molecules which characteristically include long chain branches. Kneading might change entanglements of such branched macromolecules significantly.

It is well-known that impact strength decreases and stress crack resistance increases as molecular weight distribution broadens for HDPE pipe materials ${ }^{14)}$. In other words, impact strength is influenced by lower molecular weight component in the material which has a broad molecular weight distribution. The reason of no change in Charpy and tensile impact strengths in this study would be that the amount of lower molecular weight component was not affected by kneading.

\section{CONCLUSION}

We can say that two kinds of rheological change exist in the HDPE polymerized by a standard Phillips $\mathrm{Cr} /$ silica catalyst. The melt elasticity was depressed by shear flow and it was known as "shear modification". Surprisingly, we found that the elasticity increased by undergoing two-roll milling. The latter modification may be called "elongational modification", because convergent flow in two-roll milling contains elongational flow. It is interesting that both modifications occur easily and reversibly. Furthermore their effects extend to the stress crack resistance in the solid state, though they do not affect to the impact strength. It is presumed that conformations and entanglements of large molecules hardly change in the time scale of rheological measurements such as linear viscoelasticity and elongational viscosity because long chain branches yield long relaxation time. It is suggested that these modifications are due to changes of conformations and entanglements of the molecules which have long chain branches.

\section{REFERENCES}

1) Hanson DE, Polym Eng Sci, 9, 405 (1969).

2) Rokudai M, J Appl Polym Sci, 23, 463 (1979).

3) Munstedt H, Colloid Polym Sci, 259, 966 (1981).

4) Leblans PJR, Bastiaansen C, Macromolecules, 22, 3312 (1989).

5) Yamaguchi M, Gogos CG, Adv Polym Technol, 20, 261 (2001).

6) Yamaguchi M, Todd DB, Gogos CG, Adv Polym Technol, 22, 179 (2003)

7) McDaniel MP, Collins KS, J Polym Sci Part A, 47, 845 (2009).

8) Yang Q, Jensen MD, McDaniel MP, Macromolecules, 43, 8836 (2010).

9) Yu Y, Schwerdtfeger E, McDaniel M, J Polym Sci Part A, 50, 1166 (2012).

10) Huang YL, Brown N, J Mater Sci, 23, 3648 (1988).

11) Weeks JJ, J Research NBS, 67A, 441 (1963).

12) Lu X, Ishikawa N, Brown N, J Polym Sci Part B: Polym Phys, 34, 1809 (1996).

13) Yoshikawa H, Toneaki N, Moteki Y, Takahashi M, Masuda T, Nihon Reoroji Gakkaishi (J Soc Rheol, Jan), 18, 87 (1990).

14) Plastic Pipe Institute, "Handbook of Polyethylene Pipe", $2^{\text {nd }}$ ed, (2008), Plastic Pipe Institute, TX. 